\title{
Recessive intellectual disability-motor dysfunction-multiple joint contractures syndrome
}

INSERM

\section{Source}

INSERM. (1999). Orphanet: an online rare disease and orphan drug data base. Recessive intellectual disability-motor dysfunction-multiple joint contractures syndrome. ORPHA:280384

Recessive intellectual disability-motor dysfunction-multiple joint contractures syndrome is a rare, genetic, syndromic intellectual disabilty disorder characterized by severe intellectual disability, progressive, postnatal, multiple joint contractures and severe motor dysfunction. Patients present arrest and regression of motor function and speech acquisition, as well as contractures which begin in lower limbs and slowly progress in an ascending manner to include spine and neck, resulting in individuals presenting a specific fixed position. 